\title{
COVID-19 Pandemi Sürecinde Çocuklardaki İnternet Bağımlılığı, Siber Mağduriyet Düzeyleri ve Algılanan Ebeveyn İzleminin İ́celenmesi
}

\author{
Enes SARIGEDIK ${ }^{1}$
}

ÖZ

Amaç: Geçtiğimiz yıl içerisinde tüm dünya COVID-19 pandemisinin etkisi altındaydı. Pandemi evlerde geçirilen süreleri artırdı. İnsanların evlerinde geçirilen sürelerine paralel olarak internette geçirdikleri süreler de arttı. Bu çalışma da bu gelişmelerin internet üzerinden zorbalığa uğrama ile olan ilişkisinin incelenmesi amaçlanmıştır.

Gereç ve Yöntemler: Katılımcılara çevrimiçi ortam üzerinden ulaşıldı. Annelerden; Sosyo-demografik form, AileÇocuk İnternet Bağımlılık Ölçeği, çocuklardan ise Siber Mağduriyet Ölçeği, Anne Baba İzleme Ölçeği doldurmaları istenmiştir. Katılmayı kabul eden katılımcılardan bilgilendirilmiş onamları alınmıştır. Toplam 104 anne ve çocuk ile çalışma tamamlanmıştır.

Bulgular: Kız cinsiyette, yaş ile siber mağduriyet ölçek puanları arasında istatistiksel olarak anlamlı pozitif yönlü zayıf bir ilişki bulunmuştur (r: 0,308, $\mathrm{p}=0,028)$. Sosyal medya hesabı olan çocuk ve ergenlerin siber mağduriyet puanları olmayanlara göre istatistiksel olarak anlamlı düzeyde daha yüksek bulunmuştur( $\mathrm{p}=0,002)$. Ölçeklerin birbirleri ile olan ilişkileri değerlendirildiğinde Aile-Çocuk İnternet Bağımlılık Ölçeği ile Siber mağduriyet düzeyleri arasında istatistiksel olarak anlamlı pozitif yönde zayıf bir ilişki olduğu saptanmıştır $(\mathrm{r}=0,248 \mathrm{p}=0,011)$. Ergen grubunda hem Aile-Çocuk İnternet Bağımlılık Ölçeği hem de Siber mağduriyet ölçeği ile kısıtlayıcı izlem arasında istatistiksel olarak anlamlı pozitif yönde zayıf düzeyde ilişki bulunmaktadır $(\mathrm{r}=0,345 \mathrm{p}=0,019 ; \mathrm{r}=0,345 \mathrm{p}=0,019)$.

Sonuç: COVID-19 sürecinde internet bağımlılığı ve siber mağduriyet gençler arasında hızla artmaktadır. Yaşın artması ve sosyal medya hesaplarının olması çocuk ve ergenlerde siber mağduriyet açısından risk yaratmaktadır. Aileler bu süreçte çocukları yakından izlemeli, internet kullanımı ve siber mağduriyet hakkında doğru bilgilendirmeler yapmalıdır, sınır koyma da aşırı kısıtlayıcı olmaktan kaçınmalıdırlar.

Anahtar Kelimeler: COVID-19; internet bağımlılı̆̆1, siber mağduriyet; ebeveyn izlemi.

\section{The Investigation of Internet Addiction, Cyber Victimization Levels and Perception of Parental Monitoring in Children During the COVID-19 Pandemic}

\begin{abstract}
Aim: People struggle with COVID-19 on all over the world last year and the time people spend at home has increased due to pandemic. In this study, we aimed to investigate the relationship between cyber victimization and COVID-19 pandemic in children.

Material and Methods: The data consist of 104 mother and child who answered the scales with the help of the online environment by Google questionnaire method. Participants were asked to fill in the socio-demographic form, the Parent-Child Internet Addiction Test, the Cyber victimization scale, the Parental Monitoring Instrument. This study was approved by the ethics committee of Düzce University Faculty of Medicine clinical studies ethics committee.

Results: In this study a statistically significant weak correlation was found between the age of female gender and the cyber victimization scale ( $\mathrm{r}: 0.308, \mathrm{p}=0.028)$. Having a social media account is statistically significantly associated with Cyber victimization scores $(\mathrm{p}=0.002)$. When the relationships of the scales with each other was evaluated, it was found that there was a statistically significant positive weak relationship between the Parent- Child Internet Addiction Test and the CVS scores $(r=0.248 \mathrm{p}=0.011)$.
\end{abstract}


There is a statistically significant positive weak correlation between both Parent- Child Internet Addiction Test and Cyber victimization scores and restrictive follow-up $(\mathrm{r}=0,327 \mathrm{p}=0,019 ; \mathrm{r}=0,345 \mathrm{p}=0,019)$.

Conclusion: Internet addiction and cyber victimization are rapidly increasing among children. Older age and having a social media account seem to be risk factors for cyber victimization. Families should follow up children closely and inform their children about harm of excessive use of internet in these ages.

Keywords: COVID-19; internet addiction; cyber victimization; parental monitoring.

\section{GIRIS}

COVID-19 pandemisi küresel etkileri olan önemli bir sorun olarak yaklaşık iki yıldır hayatımız da yer alıyor. COVID-19 ile mücadele amacı ile devletler, kişisel ve toplumsal olarak birçok alanda önlem almak zorunda kaldılar. Kişisel ve toplumsal bu önlemler hepimizin hayatında önemli değişikliklere neden oldu. $\mathrm{Bu}$ tedbirlerin sonucunda insanlar arasındaki yüz yüze iletişim azaldı, insanlar sosyal hayatlarından uzaklaştılar ve evde geçirilen süreler arttı.

COVID-19 kaynaklı yaşam değişiklikleri, teknolojik araçların kullanım alışkanlıklarımızı da etkiledi. İnsanlar çevrimiçi görüşme yöntemlerini daha fazla kullanmaya başladılar(1). Çocuk ve ergenler ise pandemi döneminde internette daha fazla vakit geçirmeye başladılar(2). Internetin fazla kullanımı, "internet bağımlılığı", "problematik internet kullanımı", "patolojik internet kullanımı" farklı isimlerle ile anılabilmektedir (3). Shapira ve arkadaşları, internet bağımlılığını; internetin aşırı kullanımı ile uyumsuz bir meşguliyet ve bireyin günlük yaşamında önemli sıkıntı veya bozulmaya neden olan aşırı kullanım olarak tanımlamışlardır (4).

COVID-19 sürecinde, gençler arasında da internet kullanımı arttığını bildiren çalışmalar bulunmaktadır $(2,5)$. Çalışmalarda yaş, dürtüsellik, yalnızlık, düşük aile işlevi gibi durumlar internet bağımlılığını artıran bağımsız ön görücüler olarak bildirilmiştir(2,5). Çocuk ve ergenler, interneti genellikle çevrimiçi oyun oynama, sosyal ağlar, pornografi, arkadaşlık siteleri gezinme gibi durumlar için yoğun olarak kullanmaktadırlar (6). İnternetin yoğun kullanımı ile birlikte siber mağduriyet ve siber zorbalık gibi durumların ortaya çıkmasında da artış görülmektedir (7).

Siber mağduriyet; internet, oyun konsolları ve cep telefonları gibi bilgi ve iletişim teknolojileri aracılığıyla saldırgan davranışlar yaşamak olarak tanımlanmaktadır (8). Siber mağduriyet sıklığı ile ilgili olarak verilen çalışmaların metodolojisine göre değişmekle birlikte \% 4 ile \%43 arasında değişkenlik gösterebilmektedir (8). Siber zorbalığa maruz kalmak çocuk ve gençler üzerinde depresyon, intihar, travma sonrası stres bozukluğu (TSSB), anksiyete bozuklukları, yeme bozuklukları, alkol kullanım bozuklukları gibi bir çok psikiyatrik hastalığa neden olabilmektedir (9-11).

Tüm bu rahatsızların nedeni olan internet bağımlılığı ve siber mağduriyet için koruyucu olan faktör olarak sağlıklı ebeveyn izlemi karşımıza çıkmaktadır (12). Ebeveyn izlemi ise Schaefer tarafından kavramlaştırılmıştır ve 3 boyutu tanımlanmıştır; kabule karşı reddetme, psikolojik özerkliğe karşı psikolojik kontrol ve sıkı kontrole karşı gevşek kontrol olmak şeklindedir (13). Ancak ebeveyn kontrolünün, utandırma, izleme, koruma, kural oluşturma, sevgiden yoksun bırakma gibi birçok şekli olabilmektedir (14).

Literatür taramamızda internet bağımlılığı, siber mağduriyet ve ebeveyn izlemini birlikte değerlendiren bir çalışmanın bulunmadığı görülmüştür. $\mathrm{Bu}$ çalışma da COVID-19 pandemisi sürecinde internet kullanımındaki artışın siber mağduriyette artışa sebep olup olmadığı, aile izlemi yöntemlerin siber mağduriyet ve internet bağımlılığı açısından koruyucu rolünü araştırmak amaçlanmıştır.

\section{GEREC VE YÖNTEMLER}

Çalışmanın çevrimiçi ortamda yapılması planlandı. Çevrimiçi anket yöntemi 18-25 Ocak 2021 tarihleri arasında katılıma açıldı. Katılmayı kabul eden katılımcılara başlangıç aşamasında hastalara bilgilendirilmiş onam form sayfası açıldı. Form onamı verilmeden çalışmaya devam edilmesi engellendi.

Hem çocuklardan hem de annelerden ayrı ayrı onamları alında. Annelerden; Sosyo-demografik form, Aile-Çocuk İnternet Bağımlılık Ölçeği (AÇİBÖ) ölçeklerini, çocuklardan ise Siber Mağduriyet Ölçeği, Anne Baba İzleme Ölçeği (ABİÖ) doldurmaları istenmiştir. Çalışmaya dahil edilme kriterleri olarak, hastaların çalışmaya katılma onamı vermeleri, 7-18 yaş aralığında olmaları, bilinen ek fiziksel hastalığa sahip olmamak kabul edilmiştir. Dişlama kriterleri olarak 7-18 yaş aralığının dışından olmak ve fiziksel bir hastalığa sahip olmak kabul edilmiştir.

Çalışmanın etik kurul aşamasında güç hesaplaması yapılmış, G-power programı kullanılarak yapılan hesaplamada, 0,80'lik çalışma gücü ve 0,3'lük küçük etkili cohen-d değeri elde etmek için gerekli olan örneklem genişliği 90 kişi olarak hesaplanmıştır(15).

Çalışma sonucunda toplamda 112 aile ve çocuğa ulaşılmış ancak yeterli sayıda soruya cevap vermeyen 6 kişi, fiziksel hastalık bildiren 2 kişi çalışmadan çıkarılmıştır. Ölçeklerde yeterli sayıda soruyu yanıtlayan ve ek fiziksel hastalığı olmayan 104 anne ve çocuk ile çalışma tamamlanmıştır. Çalışmanın etik kurul onayı Düzce Üniversitesi Tıp Fakültesi klinik çalışmalar etik kurulundan (2020/270) alınmıştır.

\section{Veri Toplama Araçları}

Sosyo-Demografik Form: Yaş, cinsiyet, sınıf düzeyi, gelir düzeyleri, internet kullanım özelikleri vb. bilgiler toplamak amaciyla araştırmacı tarafindan oluşturulmuştur.

Aile-Çocuk İnternet Bağımlılık Ölçeği (AÇiBÖ̈): Orijinal adı "Parent- Child Internet Addiction Test, PCIAT20)" olan ölçek Young tarafından geliştirilmiştir. Geçerlilik güvenilirlik çalışması 2014 yılında Eşgi tarafından yapılmış ve Türkçeye uyarlanmıştır.18 soruluk likert tipi bir ölçektir ve katılımcılar 0-5 arasında soruları puanlamaktadır. Cronbah Alfa değeri 0,91'dir(16).

Siber mağduriyet ölçeği: Arıcak ve arkadaşları tarafından Türk popülasyonda geliştirilen ölçeğin geçerlilik güvenirliliği yapılmıştır. Ölçekte toplam 24 madde bulunmaktadır ve her madde "Evet" ya da "Hayır" şeklinde cevaplanmaktadır. "Evet" yanıtı iki puan, "Hayır" yanıtı bir puan almaktadır. Tersine madde yoktur. Ölçekten elde edilen en düşük puan 24, en yüksek 
puan 48 olmaktadır. Puanların yükselmesi siber mağduriyetin arttığına işaret etmektedir. Ölçek için Cronbah Alfa değeri 0,89 , test-tekrar katsayısı ise 0,75 bulunmuştur(17).

Anne Baba İzleme Ölçeği (ABİÖ): Cotrell ve arkadaşları tarafından 'Parental Monitoring Instrument (PMI)' adı ile 2007 yılında geliştirilen ölçek Karataş ve Öztürk tarafından 2011 yılından Türkçeye çevrilmiş ve geçerlilik güvenilirlik çalışması yapılmıştır. 27 maddeden oluşan ölçekte toplam puan bulunmamaktadır ve 7 alt boyuttan ( Dolaylı İzlem, Doğrudan İzlem, Sağlık İzlemi, Bilgisayar İzlemi, Telefon İzlemi, Kısıtlayıcı İzlem) oluşmaktadir(18,19).

\section{İstatistiksel Analiz}

Verilerin değerlendirilmesinde SPSS 26.0 paket programı kullanılmıştır. Tanımlayıcı değişkenlerin sunulmasında ortalama, standart sapma, sayı, yüzde; non-parametrik dağılım gösteren veriler için ortanca, çeyrekler arası açıklık değerleri verilmiştir. Sayısal değişkenlerin normal dağılım gösterip göstermediği Kolmogorov-Smirnov testi ile değerlendirilmiştir. Normal dağılım gösteren iki grup karşılattırmasında bağımsız gruplar için t testi, İki grubun normal dağılım gösteren sayısal değişkenler bakımından karşılaştırılmasında Mann Whitney U testi kullanılmıştır. İkiden fazla grubun normal dağılım gösteren sayısal değişkenler bakımından karşılaştırılmasında One Way Anova, normal dağılım göstermeyen sayısal değişkenler bakımından karşılaştırılmasında ise Kruskal-Wallis testi kullanılmıştır. Normal dağılım gösteren sayısal değişkenler arasındaki korelasyonlar Pearson korelasyon katsayısı, normal dağılmayan sayısal değişkenler arasındaki korelasyonlar Spearman korelasyon katsayısı ile değerlendirilmiştir. İstatistiksel anlamlılık $\mathrm{p}<0,05$ kabul edilmiştir.

\section{BULGULAR}

Katılımcıların sosyo-demografik özellikleri ve siber mağduriyet ve aile çocuk internet bağımlılık (AÇi்Ö) ile olan ilişkileri Tablo-1'de özetlenmiştir. Çalışma toplam 104 katılımcı ile tamamlanmıştır, katılımcıların \%51'i kız, \%49 ise erkeklerden oluşmuştur. Katılımcıların ortalama yaşı 9,66 $\pm 2,51$ 'dir. Yaş ile ilgili olarak kız cinsiyette yaş ile siber mağduriyet ölçeği arasında istatistiksel olarak anlamlı zayıf derecede ilişki bulunmuştur (r: 0,308, p:0,028). Çocuklar pandemi sürecinde internette ortalama $5,89 \pm 2,6$ saat zaman geçirirken, ders haricinde internette geçirdikleri zaman 2,33 $\pm 1,66$ saat olarak bulunmuştur. Ayrıca çocuklar pandemi sürecinde ortalama 3 saat daha fazla internette vakit geçirmektedirler. AÇİBÖ ile internette geçirilen süre arasında istatistiksel olarak anlamlı zayıf düzeyde ilişki varken, ders haricinde geçirilen süre ve pandemi döneminde internet kullanımındaki artış ile istatistiksel olarak anlamlı orta düzeyde ilişki bulunmuştur (sırasıyla r: 0,281, p:0,004; r: 0,598, p<0,01; r: 0,475, p<0,01) (Tablo 1).

Ebeveyn izlem ölçeğinin alt ölçekleri ile yaş arasındaki ilişki incelendiğinde yaş ile dolaylı izlem, okul izlemi, bilgisayar izlemi arasında istatistiksel olarak anlamlı negatif yönde zayıf düzeyde ilişki bulunmuştur (sırasıyla r:-,211*, p=0,032; r: -,208, p=0,034; r:-,249, p=0,011; r: ,237, p=0,015) (Tablo-2). Ders haricinde internette geçirilen süre ile kısıtlayıcı gözlem arasında istatistiksel olarak anlamlı pozitif yönde zayıf düzeyde ilişki bulunmuştur (r: 0,272, $\mathrm{p}=0,005)$.

Tablo 1. Yaş ve sosyodemografik özellikler ile AÇi̇BÖ ve siber mağduriyet ölçeklerinin korelasyonları

\begin{tabular}{|c|c|c|c|c|c|c|c|}
\hline & & \multirow[t]{2}{*}{$\mathrm{n}(\%)$} & \multirow[t]{2}{*}{$\operatorname{ort} \pm \mathrm{SS}$} & \multicolumn{2}{|c|}{ AÇі் ÖB } & \multicolumn{2}{|c|}{ Siber mağduriyet } \\
\hline & & & & $\mathrm{r}$ & $\mathrm{p}$ & $\mathrm{r}$ & $\mathrm{p}$ \\
\hline \multirow[t]{3}{*}{ YAŞ } & Erkek & $51(49)$ & $9,5 \pm 2,65$ & ,196 & 0,160 &, 145 & 0,301 \\
\hline & Kadın & $53(51)$ & $9,81 \pm 2,40$ & ,263 & 0,062 & ,308 & 0,028 \\
\hline & Toplam & 104(100) & $9,66 \pm 2,51$ & ,248 & 0,011 & ,239 & 0,015 \\
\hline \multicolumn{3}{|c|}{ İnternette geçirilen toplam süre(saat) } & $5,89 \pm 2,6$ & ,281 & 0,004 & 134 & 0,176 \\
\hline \multicolumn{3}{|c|}{$\begin{array}{l}\text { Ders haricinde internette geçirilen } \\
\text { süre(saat) }\end{array}$} & $2,33 \pm 1,66$ &, 598 & $<0.01$ & ,153 & 0,120 \\
\hline \multicolumn{3}{|c|}{$\begin{array}{l}\text { Pandemi sürecinde ortalama internette } \\
\text { geçirilen süre artış1(saat) }\end{array}$} & $2,67 \pm 2,30$ & ,475 & $<0.01$ & ,038 & 0,701 \\
\hline
\end{tabular}

Spearman korelasyon testi, r; AÇi்B̈̈: Aile-Çocuk İnternet Bağımlılık Ölçeği, ort: ortalama, SS: standart sapma, ÇAA: çeyrekler arası açıklık 
Tablo 2. Sosyo-demografik özelikler, internet kullanımı ve ebeveyn izlemi alt ölçekleri arasındaki ilișkinin incelenmesi

\begin{tabular}{|c|c|c|c|c|c|c|c|c|c|c|c|c|c|c|}
\hline & \multicolumn{2}{|c|}{ Dolaylı } & \multicolumn{2}{|c|}{ Doğrudan } & \multicolumn{2}{|l|}{ Okul } & \multicolumn{2}{|c|}{ Sağlık } & \multicolumn{2}{|c|}{ Bilgisayar } & \multicolumn{2}{|c|}{ Telefon } & \multicolumn{2}{|c|}{ Kısıtlayıc1 } \\
\hline & $\mathrm{r}$ & $\mathrm{p}$ & $\mathrm{r}$ & $\mathrm{p}$ & $\mathrm{r}$ & $\mathrm{p}$ & $\mathrm{r}$ & $\mathrm{p}$ & $\mathrm{r}$ & $\mathrm{p}$ & $\mathrm{r}$ & $\mathrm{p}$ & $\mathrm{r}$ & $\mathrm{p}$ \\
\hline Yaş &,- 211 & 0,03 & $-0,06$ & 0,55 &,- 208 & 0,034 & $-0,25$ & 0,01 &,- 237 & 0,015 &,- 123 & 0,22 & ,047 & 0,636 \\
\hline $\begin{array}{l}\text { İnternette } \\
\text { geçirilen zaman } \\
\text { toplam(saat) }\end{array}$ & $-0,21$ & 0,03 & ,066 & 0,51 & - 098 & 0,324 & , 050 & 0,613 & 0,177 & 0,073 & ,072 & 0,47 & 0,15 & 0,129 \\
\hline $\begin{array}{l}\text { Ders haricinde } \\
\text { internette } \\
\text { geçirilen } \\
\text { süre(saat) }\end{array}$ & ,037 & 0,71 & ,037 & 0,71 &,- 061 & 0,537 &,- 015 & 0,877 & (097 & 0,328 & ,078 & 0,43 & ,272 & 0,005 \\
\hline $\begin{array}{l}\text { Pandemi } \\
\text { sürecinde } \\
\text { ortalama } \\
\text { internette } \\
\text { geçirilen süre } \\
\text { artış1(saat) }\end{array}$ & ,041 & 0,67 & $-0,01$ & 0,99 & ,044 & 0,662 & ,045 & 0,652 & ,209 & 0,034 & , 109 & 0,27 & ,102 & 0,306 \\
\hline
\end{tabular}

Evdeki internet kullanımı ile ölçek puanları karşılaştırıldığında, sosyal medya hesabı olan çocukların hem siber mağduriyet hem de AÇİBÖ puanları açısından istatistiksel olarak anlamlı daha yüksek puanlar almışlardır ( $\mathrm{p}=0,002, \mathrm{p}=0,001)$ (Tablo 3).
Ayrıca pandemi sürecinde internet kullanımı artan grupta AÇIBÖ puanları istatistiksel olarak anlamlı daha yüksek bulunmuştur $(\mathrm{p}<0,01)$.

Tablo 3. Bilgisayar kullanımı ile ilgili nitel özeliklerin AÇİBÖ ve siber mağduriyet düzeyleri ile ilişkisinin incelenmesi

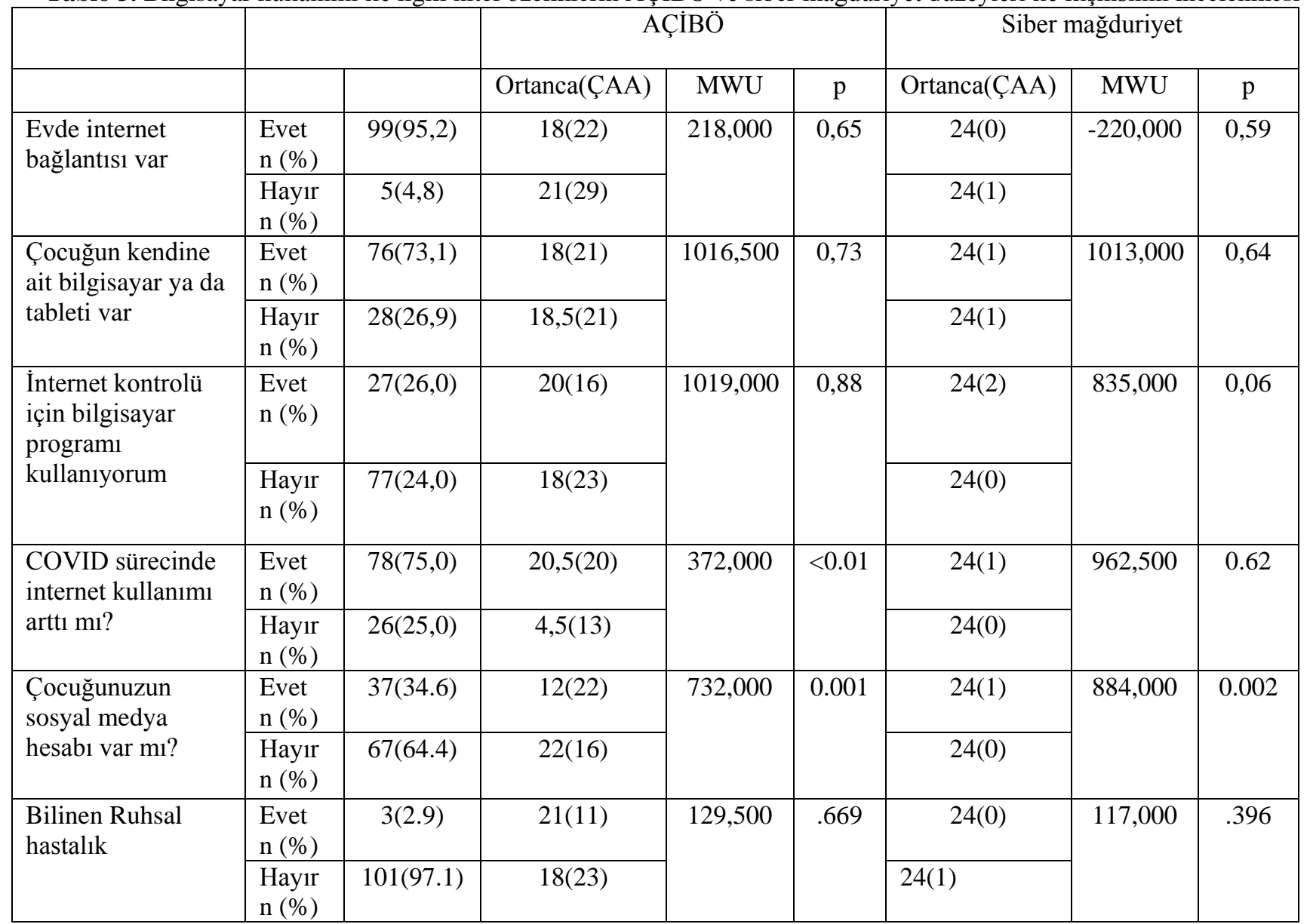

Mann-Whitney U test, AÇiBÖ: Aile-Çocuk İnternet Bağımlılık Ölçeği 
Yaş grubuna göre ölçek puanlarının incelemesi Tablo 4'te verilmiştir. 12 yaş ve üzerindekiler ergen grubuna dahil edilirken diğer yaş grupları çocuk grubunda değerlendirilmiştir. Katılımcıların \%55,8'i çocuk, \%44,2'si ergendir. Ergenlerin, istatistik olarak anlamlı düzeyde siber mağduriyet yaşadıkları bulunmuştur( $\mathrm{p}=0,018)$.

Ebeveyn izlemi alt ölçekleri açısından sağlık izlemi ve bilgisayar izlemi ortanca puanları ergenlerde çocuklardan istatistiksel olarak anlamlı düzeyde düşük bulunmuştur (sirasiyla $\mathrm{p}=0,013, \mathrm{p}: 0,048$ ).

Ölçeklerin birbirleri ile olan ilişkileri değerlendirildiğinde AÇIBÖ ile Siber mağduriyet düzeyleri arasından istatistiksel olarak anlamlı pozitif yönde zayıf bir ilişki olduğu saptanmıştır $(r=0,248 \mathrm{p}=0,011)$ (Tablo-5). Hem AÇi்Ö hem de Siber mağduriyet ölçeği ile kısıtlayıcı izlem arasında istatistiksel olarak anlamlı pozitif yönde zayıf düzeyde ilişki bulunmaktadır ( $\mathrm{r}=0,319 \mathrm{p}=0,001$; $\mathrm{r}=0,239 \mathrm{p}=0,015)$.

Tablo 4. AÇİBÖ, siber mağduriyet ve ebeveyn izlemi ölçeklerinin çocuk ve ergenlere göre incelenmesi

\begin{tabular}{|l|c|c|c|c|}
\hline & Çocuk(n:58) & Ergen(n:46) & MWU & p \\
\hline & Ortanca(ÇAA) & Ortanca(ÇAA) & 1062,500 & 0,075 \\
\hline AÇİBÖ & $14(24)$ & $21(21)$ & 1049,500 & 0,018 \\
\hline Siber mağduriyet & $24(0)$ & $24(1)$ & & 0,911 \\
\hline Ebeveyn izlem & & & 1057,000 & 0,275 \\
\hline Dolaylı & $16(6)$ & $14(6)$ & 1317,000 & 0,013 \\
\hline Doğrudan & $7(4)$ & $7(4)$ & 1169,000 & 0,048 \\
\hline Okul & $10(4)$ & $10(3)$ & 957,000 & 0,117 \\
\hline Sağlık & $10(4)$ & $8.5(5)$ & 1033,500 & 0,834 \\
\hline Bilgisayar & $9(5)$ & $7(5)$ & 1102,500 & 1307,500 \\
\hline Telefon & $4(2)$ & $3(2)$ & $3(1)$ & \\
\hline Kisıtlayıcı & $3(1)$ & & & \\
\hline
\end{tabular}

Mann-Whitney U Test, AÇİBÖ: Aile-Çocuk İnternet Bağımlılık Ölçeği,

Tablo 5. AÇı̇BÖ, Siber Mağduriyet ve Ebeveyn izlem ölçeklerinin birbirleri ile korelasyonlarının incelenmesi

\begin{tabular}{|c|c|c|c|c|c|c|c|c|}
\hline & \multicolumn{4}{|c|}{ Çocuk } & \multicolumn{4}{|l|}{ Ergen } \\
\hline & \multicolumn{2}{|c|}{ AÇі்BÖ } & \multicolumn{2}{|c|}{ Siber Mağdur } & \multicolumn{2}{|c|}{ AÇїBÖ } & \multicolumn{2}{|c|}{ Siber mağdur } \\
\hline & $\mathrm{r}$ & $\mathrm{p}$ & $\mathrm{r}$ & $\mathrm{p}$ & $\mathrm{r}$ & $\mathrm{p}$ & $\mathrm{r}$ & $\mathrm{p}$ \\
\hline AÇİBÖ & 1 & & ,309 & 0,018 & 1 & & 0,89 & 0,556 \\
\hline \multicolumn{9}{|c|}{ Ebeveyn izlem } \\
\hline Dolaylı &, 062 & 0,642 & ,009 & 0,945 & 0,366 & 0,012 & 0150 & 0,321 \\
\hline Doğrudan &,- 052 & 0,697 &,- 008 & 0,954 & 0,260 & 0,08 & 0,013 & 0,930 \\
\hline Okul & ,071 & 0,596 &,- 004 & 0,975 & 0,03 & 0,846 & $-0,260$ & 0,081 \\
\hline Sağlık & ,139 & 0,299 & ,066 & 0,624 & 0,114 & 0,449 & 0,82 & 0,588 \\
\hline Bilgisayar & ,194 & 0,144 &,- 014 & 0,918 & 0,239 & 0,109 & 0,227 & 0,129 \\
\hline Telefon & ,021 & 0,878 & ,030 & 0,823 & 0,187 & 0,214 & 0,023 & 0,879 \\
\hline Kisitlayıcı & ,327 & 0,012 & ,153 & 0,250 & ,345 & 0,019 & 0,345 & 0,019 \\
\hline
\end{tabular}

Spearman korelasyon testi,. AÇi̇BÖ: Aile-Çocuk İnternet Bağımlılık Ölçeği 


\section{TARTISMA}

COVID-19 sürecinde internet kullanımındaki artış, siber mağduriyet değerlendirilmesi gereken önemli konular arasında yer almaktadır. İnternet bağımlılığı genellikle öz bildirime dayalı olarak değerlendirilir. Ancak pandemi sürecinde ailelerin çocuklarla birlikte geçirdikleri sürelerin artması ile beraber aile gözlemleri de internet bağımlılığı değerlendirmek için iyi bir gösterge olarak kullanılabilir. Çalışmamıza göre pandemi sürecinde internet kullanımı ortalama 3 saat artmıştır, sosyal medya hesabının olması ve yaşın büyümesi siber mağduriyet yaşama riskini artırmaktadır. Çocuk yaş grubunda ebeveynleri tarafindan sağlık ve bilgisayar izlemi daha sık yapılmaktadır. Ailelerini kısıtlayıcı ebeveynlik stiline sahip olarak değerlendiren ergenlerde, siber mağduriyet riski arttırmaktadır.

Katılımcılar arasında siber mağduriyet ve yaş arasında anlamlı bir korelasyon varken ölçek puanlarına bakıldığında puanlar arasında anlamlı bir fark bulunamamıştır. Yazın incelendiğinde, siber mağduriyet ve cinsiyet arasında karmaşık sonuçlar bulunmaktadır bazı araştırmacılar erkeklerde, bazı araştırmacılar ise kızların daha fazla siber mağduriyete yaşadıklarını bildirirken cinsiyetler arasında fark bulunmadığını iddia eden araştırmacılarda bulunmaktadır(20-23). İspanya da yapılan çalışmada kızlarda belirgin olarak mağduriyetin daha yüksek olduğu ve bunun kadınsı özeliklerle ilgili olabileceğini ileri sürmüşlerdir(24). Bizim çalışmamızda ortanca yaş 9 ve ergenlik öncesi dönemde ikincil cinsiyet özeliklerinin gelişmemiş olması, siber mağduriyet açısından anlamlı fark bulunmamasına sebebiyet vermiş olabilir.

Yaşa göre ölçeklerin birbirine göre korelasyonlarına bakıldığında ise çocuklarda, siber mağduriyet ile aile internet bağımlılığı ölçeği arasında ilişki varken, ergen grubunda ise korelasyon kurulamamıştır. Ailelerine göre daha fazla internet bağımlılı̆̆ı olan çocuklar, siber mağduriyet açısından daha fazla risk taşımaktadırlar. Ergen yaş grubunda ise bu ilişki kurulamamıştır. Ergenlik döneminde aileden ayrılma, tek başına geçirilen sürelerin artması gibi nedenlerde internet kullanımı ile ilgili sürenin değerlendirilmesin aile tarafindan takip edilmemesinin sonuçlarımızı etkilemiş olabileceği düşünülmüştür. Bu konuyu değerlendirmek için ergen yaş grubunda öz-bildirim ölçeklerin ile beraber siber mağduriyeti değerlendirmek daha sağlıklı sonuçlar verebilir.

Ergenlerin, çocuklara göre daha fazla siber mağduriyete uğradıkları bulunmuştur, ergenlerin dönemsel olarak risk alma davranışlarının artmaktadır ve hızlı bir değişim içindedirler. Yazında da lise dönemine geçildikçe siber mağduriyet düzeylerinin arttığı görülmektedir (25). Bizim çalışmamızda da yazına paralel olarak ergenlerin daha fazla siber mağduriyet yaşadıkları bulunmuştur. Bu çalışmamızdaki diğer sonuçlarla da uyumludur yaş artıkça sosyal medya hesabı kullanımı artmaktadır, sosyal medya hesabı olan kullanıcılarda daha fazla siber mağduriyet yaşamaktadırlar.

İnternette geçirilen toplam süre ile siber mağduriyet arasında istatistiksel olarak anlamlı bir fark bulunamamıştır. Yazında ise tersi bir durumdan bahsedilir. İnternette bağımlılığı arttıkça siber zorbalık ve mağduriyet düzeylerini bildiren çalıșmalar yoğunluktadır $(26,27)$. İnternette geçirilen süre çok geniş bir alanı kapsamaktadır, çocuk ve ergenler interneti ödev, oyun, film gibi birçok nedenle kullanabilirler. Pandemi sürecinde özelikle derslerin online ortama taşınması çocuk ve ergenlerin internette geçirdiği süreleri arttırmıştır. $\mathrm{Bu}$ çalışma da internetti hangi amaçla ne kadar kullandıkları özel olarak değerlendirilmemiştir. Ayrıca klinik görüşme ile internet bağımlılıkları klinisyen tarafından değerlendirilmemiştir. $\mathrm{Bu}$ nedenlerle sonuçlarımızı literatür ile uyumlu olmamış olabilir.

Siber mağduriyet, sosyal medya hesabı olan çocuk ve ergenler de anlamlı düzeyde daha yüksek bulunmuştur. Siber mağduriyet telefonla, mail yoluyla, çevrimiçi oyunlar gibi çok farklı yollarla meydana gelebilmektedir (28). Bu konudaki çalışmaların yöneldiği konulardan birisi de siber mağduriyet hangi teknolojik alet ve yöntemle oluştuğudur(29). $\mathrm{Bu}$ çalışmada değerlendirilememiş olsa da kızların erkeklere göre mobil cihazlar ile mağduriyetinin daha yüksek olduğu gösterilmiştir (29). Sosyal medya ülkemizde genelde gençler tarafından aktif kullanılmaktadır, sosyal medyaya sahip olmak aslında siber zorbalık yapmak ve siber zorbalığa uğrama oranları ile de yakından ilişkili kabul edilir (30). Bizim çalışmamızda literatürle uyumlu bir sonuç elde edilmiştir. Burada dikkati çeken önemli bir nokta ise ergenlerin sosyal medya hesaplarını daha fazla kullanmasına rağmen, ebeveyn izlem algıları bilgisayar izlemi, çocuk yaş grubundan daha az olmasıdır. Ergenlik döneminde ailelerin teknolojik izlemlerini artırmaları, ergenler için siber mağduriyet açısından daha koruyucu olabilir.

Ebeveyn izlemi ölçeğinin alt alanlarından sadece kısıtlayıcı gözlem ile siber mağduriyet arasında anlamlı korelasyon bulunmuştur. Kısıtlayıcı izlemin hem internet bağımlılığı ile hem de siber mağduriyet ile ilişkili olduğu bulunmuştur. Yazında internet bağımlılığı ile kısıtlayıcı ebeveyn izlemi ve siber mağduriyet ilişkisi değerlendiren bir çalışma bulunamamıştır. Ancak genel olarak çalışmalara baktığımız da sağlıklı ebeveyn izlemi olan çocukların internet ve bilgisayar kullanımına sınır koyabildikleri, çocukların boş zamanlarında neler yaptıklarını bildiklerini ve buna göre önlem aldıklarını, bunun sonucunda çocuk ve ergenlerin interneti daha yararlı kullanabildiklerini ifade edilmiştir (31). Ayrıca çocuk ve ergenler tarafindan algilanan ebeveyn izlemi daha az olduğunda, çocuk ve ergenlerin daha riskli davranışlarda bulunma oranı artmaktadır (32). Kısıtlayıcı ebeveyn izlemi özel alanı da zapt ederek izinsiz şekilde çocuğu kontrol etmeyi içerir, bu ebeveynlik stilinde çocukların daha fazla siber mağduriyet ve internet bağımlılığı ile ilişkili olması, katı ve otoriter ebeveynlik izleminin çocuklar için koruyucu olmaktan çok onları siber mağduriyet açısından daha riskli hale getirmektedir. Çalışma birbirlerinin gözünden anne ve çocukların gözlemlerini içermesi ve çocuk ve ergenlerin kıyaslanması açısından önemlidir. Çalışmamızın kısıtlılıkları arasında yüz yüze görüşme yapılmaması ve ruhsal hastalıkların değerlendirilmemesi sayılabilir. Ayrıca internetin en çok hangi amaçla kullanıldığı, siber mağduriyetin hangi yöntemle gerçekleştiğinde değerlendirilmemesi kısıtlılık olarak değerlendirilebilir. 


\section{SONUÇ}

$\mathrm{Bu}$ çalışmanın COVID-19 döneminde internet kullanımının arttığını, bunun internet bağımlılığı için risk faktörü olabileceğini, çocuk yaş grubunda internet bağımlılığının artmasının siber mağduriyet yaşama düzeylerini arttırabileceğini ailelerin bu konuda dikkatli olmaları gerektiğini ancak ebeveyn izlemi sırasında kısıtlayıcı ya da çocukların haklarını görmezden gelmelerinin bu konu da risk arttırıcı bir etmen olduğunu göz önünde bulundurmalarının önemli olduğuna vurgu yapmaktadır. Ergen yaş grubunda riskin artmasına rağmen bilgisayar izleminin çocuk grubuna göre azaldığ görülmemektedir. Aileler bu yaş grubunda kisitlamalar yerine sağlıklı teknolojik alet kullanımını konusunda uzmanlar tarafından daha fazla bilgilendirilmelidirler. Gelecek çalışmalar için daha geniş kapsamlı ebeveyn izleminin çocuklardaki internet kullanımını nasıl etkilediğine bakılabilir. Ayrıca siber- mağduriyeti hangi teknolojik yöntem ile gerçekleştiği ve pandemi sürecinde bu yöntemlerin değişip değişmediği incelenebilir. Başka bir başlık altında çocuk ve ergenlerin siber mağduriyet durumlarını aileleri ile paylaşma durumları ve paylaşmasını etkileyen durumların incelenmesi araştırmacılar açısından önemli olabilir.

Yazarların Katkıları: Fikir/Kavram: E.S.; Tasarım: E.S.; Veri Toplama: E.S.; Analiz ve Yorum: E.S.; Literatür Taraması: E.S.; Makale Yazımı: E.S.; Eleştirel İnceleme: E.S.

\section{KAYNAKLAR}

1. Dubey MJ, Ghosh R, Chatterjee S, Biswas P, Chatterjee S, Dubey S. COVID-19 and addiction. Diabetes Metab Syndr. 2020; 14(5): 817-23. https://doi.org/10.1016/j.dsx.2020.06.008.

2. Dong H, Yang F, Lu X, Hao W. Internet addiction and related psychological factors among children and adolescents in china during the coronavirus disease 2019 (COVID-19) epidemic. Front Psychiatry. 2020; 11: 00751. https://doi.org/10.3389/fpsyt.2020.00751

3. Coskun M, Hajdini A, Alnak A, Karayagmurlu A. Internet use habits, parental control and psychiatric comorbidity in young subjects with asperger syndrome. J Autism Dev Disord. 2020; 50(1): 171-9.

4. Shapira NA, Lessig MC, Goldsmith TD, Szabo ST, Lazoritz M, Gold MS, et al. Problematic internet use: proposed classification and diagnostic criteria. Depress Anxiety. 2003; 17(4): 207-16. https://doi.org/10.1002/da.10094.

5. Lin MP. Prevalence of internet addiction during the covid-19 outbreak and its risk factors among junior high school students in taiwan. Int $\mathrm{J}$ Environ Res Public Health. 2020; 17(22):8 547. https://doi.org/10.3390/ijerph17228547

6. Cheng C, Lau YC, Luk JW. Social capital-accrual, escape-from-self, and time-displacement effects of internet use during the covid-19 stay-at-home period: Prospective, quantitative survey study. J Med Internet $\begin{array}{lll}\text { Res. 2020; } & \text { 22(12): }\end{array}$ https://doi.org/10.2196/22740.

7. Chang FC, Chiu CH, Miao NF, Chen PH, Lee CM, Huang TF, et al. Online gaming and risks predict cyberbullying perpetration and victimization in adolescents. Int J Public Health. 2015; 60(2): 257-66. https://doi.org/10.1007/s00038-014-0643-x.

8. Wright MF, Wachs S. Adolescents' cyber victimization: The Influence of technologies, gender, and gender stereotype traits. Int J Environ Res Public Health. $2020 ; \quad 17(4)$ : 1293. https://doi.org/10.3390/ijerph17041293

9. Marco JH, Tormo-Irun MP. Cyber victimization is associated with eating disorder psychopathology in adolescents. Front Psychol. 2018;9:987. https://doi.org/10.3389/fpsyg.2018.00987.

10. Yang F. Coping strategies, cyberbullying behaviors, and depression among Chinese netizens during the COVID-19 pandemic: a web-based nationwide survey. J Affect Disord. 2021; 281: 138-44. https://doi.org/10.1016/j.jad.2020.12.023

11. Chan SF, La Greca AM, Peugh JL. Cyber victimization, cyber aggression, and adolescent alcohol use: Short-term prospective and reciprocal associations. J Adolesc. 2019; 74: 13-23. https://doi.org/10.1016/j.adolescence.2019.05.003.

12. Wang W, Li D, Li X, Wang Y, Sun W, Zhao L, et al. Parent-adolescent relationship and adolescent internet addiction: A moderated mediation model. Addict Behav. 2018; 84: 171-7. https://doi.org/10.1016/j.addbeh.2018.04.015.

13. Schaefer ES. Children's reports of parental behavior: An inventory. Child Development. 1965; 36(2): 41324.

14. Kındap Y, Sayıl M, Kumru A. Anneden algilanan kontrolün niteliği ile ergenin psikososyal uyumu ve arkadaşlıkları arasındaki ilişkiler: Benlik değerinin aracı rolü. Türk Psikoloji Dergisi. 2008; 23(61): 92107.

15. Faul F, Erdfelder E, Buchner A, Lang AG. Statistical power analyses using $\mathrm{G}^{*}$ Power 3.1: Tests for correlation and regression analyses. Behavior Research Methods 2009; 41: 1149-60. https://doi.org//10.3758/BRM.41.4.1149

16. Eşgi N. Aile-Çocuk İnternet Bağımlılık Ölçeği'nin Türkçeye uyarlanması: Geçerlik ve güvenirlik çalışması. Kastamonu Eğitim Dergisi. 2014; 22(2): 807-39.

17. Aricak O, Tanrikulu T, Kinay H. Siber mağduriyet ölçeğinin ilk psikometrik bulguları. Akdeniz Eğitim Araştırmaları Dergisi. 2012; 6(11): 1-6.

18. Cottrell SA, Branstetter S, Cottrell L, Harris CV, Rishel C, Stanton BF. Development and Validation of a parental monitoring instrument: Measuring how parents monitor adolescents' activities and risk behaviors. The Family Journal. 2007; 15(4): 328-35. https://doi.org/10.1177/1066480707303748

19. Karataş H, Öztürk C. Anne-Baba İzleme Ölçeğinin psikometrik özellikleri. Anadolu Psikiyatri Dergisi 2011; 12: 151-7.

20. Wachs S, Junger M, Sittichai R. Traditional, Cyber and combined bullying roles: Differences in risky online and offline activities. Societies. 2015; 5(1): 109-35. https://doi.org//10.3390/soc501010

21. König A, Gollwitzer M, Steffgen G. Cyberbullying as an act of revenge? Australian Journal of Guidance and Counselling, 2010; 20: 210-24. https://doi.org/10.1375/ajgc.20.2.210 
22. Erdur-Baker Ö. Cyberbullying and its correlation to traditional bullying, gender and frequent and risky usage of internet-mediated communication tools. New Media \& Society. 2010; 12(1): 109-25. https://doi.org/10.1177/1461444809341260

23. Huang Y, Chou C. An analysis of multiple factors of cyberbullying among junior high school students in Taiwan. Computers in Human Behavior. 2010; 26(6): 1581-90. https://doi.org/10.1016/j.chb.2010.06.005

24. Navarro R, Larrañaga E, Yubero S. Bullyingvictimization problems and aggressive tendencies in Spanish secondary schools students: the role of gender stereotypical traits. Soc Psychol Educ. 2011; 14(4): 457-73. https://doi.org/10.1007/S11218-0119163-1

25. Beale AV, Hall KR. Cyberbullying: What school administrators (and parents) can do. the clearing house: a journal of educational strategies. Issues and Ideas. $\quad 2007 ; \quad 81(1)$ : 2 8-12. https://doi.org//10.3200/TCHS.81.1.8-12

26. Manap A. İlköğretim ikinci kademe öğrencileri ve siber zorbalık: Samsun ili örneği. [YÖK Ulusal Tez Merkezi]: Ondokuz Mayıs Üniversitesi; 2012.

27. Méndez I, Jorquera AB, Esteban CR, GarcíaFernandez JM. Profiles of problematic internet use in bullying and cyberbullying among adolescents. Int $\mathbf{J}$ Environ Res Public Health. 2020; 17(19): 7041. https://doi.org/10.3390/ijerph17197041.

28. Underwood MK, Ehrenreich SE. The power and the pain of adolescents' digital communication: Cyber victimization and the perils of lurking. Am Psychol. 2017; 72(2): 144-58. https://doi.org/10.1037/a0040429

29. Görzig A, Frumkin LA. Cyberbullying experiences on-the-go: When social media can become distressing. Cyberpsychology: Journal of Psychosocial Research on Cyberspace, 2013; 7(1): 4. https://doi.org//10.5817/CP2013-1-4

30. Mishna F, Saini M, Solomon S. Ongoing and online: Children and youth's perceptions of cyber bullying. Children and Youth Services Review. 2009; 31(12): 1222-8. https://doi.org//10.1016/j.childyouth.2009.05.004

31. Heim J, Brandtzæg PB, Kaare BH, Endestad T, Torgersen L. Children's usage of media technologies and psychosocial factors. New Media \& Society. 2007; $\quad 9(3)$ : 425-54. https://doi.org/10.1177/1461444807076971

32. Li X, Stanton B, Feigelman S. Impact of perceived parental monitoring on adolescent risk behavior over 4 years. J Adolesc Health. 2000; 27(1): 49-56. https://doi.org/10.1016/s1054-139x(00)00092-6. 